\title{
Experimental Study of a Two-Phase Thermosyphon Loop in Conditions of High Fluidic and Thermal Loads
}

\author{
S. Adjmi ${ }^{1}$, S. Launay ${ }^{2}$ and C. Abid ${ }^{2}$ \\ ${ }^{1}$ Chadli Bendjedid Univ, LPM, El Tarf, 36000, Algérie \\ ${ }^{2}$ Aix Marseille Univ, CNRS, IUSTI, Marseille, 13453, France \\ $\dagger$ Corresponding Author Email: adjmi-samah@univ-eltarf.dz
}

(Received April 10, 2018; accepted June 14, 2018)

\begin{abstract}
An experimental study was conducted on a two-phase thermosyphon loop with a total length of $2.1 \mathrm{~m}$, using Ethanol as a working fluid. The influence of the filling ratio, at 40 and $62 \%$, on the thermo-hydraulic behavior was investigated. The applied heat fluxes on the evaporator are ranged between 10 and $60 \mathrm{~W} / \mathrm{cm}^{2}$, which corresponds to high values compared to those published elsewhere. One can notice that the confinement conditions associated with high filling ratios contribute to the training of the liquid phase from the evaporator to the condenser, which increases the drying limit of the evaporator due to a significant increase of the flow rate of the sub-cooled liquid at the inlet of the evaporator.
\end{abstract}

Keywords: Liquid-vapor; Heat flux; Thermal resistance; Filling ratio; Heat transfer; Gravity.

\section{NOMENCLATURE}

$\begin{array}{ll}\text { b } & \text { wall } \\ \text { D } & \text { diameter } \\ \text { cond } & \text { condenser } \\ \text { evap } & \text { evaporator } \\ \text { in_c } & \text { inlet of the condenser } \\ \text { in-e } & \text { inlet of the evaporator } \\ l & \text { length of the line } \\ \text { liq } & \text { liquid } \\ \dot{m} & \text { massic flow rate } \\ \text { out_c } & \text { outlet of the condenser } \\ \text { out_e } & \text { outlet of the evaporator } \\ \text { P } & \text { pressure }\end{array}$

\section{INTRODUCTION}

The two-phase liquid-vapor thermosyphons have various advantages in the efficient transfer of heat flux, whether in the simplicity of their design or in the fact that they do not require active pumping for the movement of the fluid. In this work, we study more specifically a thermosyphon loop. This latter conventionally consists of an evaporator and a condenser, connected at their extremities by adiabatic ducts. However unlike a conventional thermosyphon shaped straight closed tube, in which the liquid and vapor flows circulating against the current, the thermosyphon loop limits this flow interaction by the continuous form of its loop.

Thus, this design has some advantages, such as its integration within the system to cool, or even in the

$\begin{array}{ll}\mathrm{Q} & \text { inlet power } \\ \mathrm{R} & \text { thermal resistance } \\ \mathrm{r} & \text { thermal résistance of the heating plate } \\ \mathrm{T} & \text { temperature } \\ \mathrm{v} & \text { electric tension } \\ & \\ \Delta \mathrm{P} & \text { differential pressure } \\ \mu & \text { dynamical viscosity } \\ \rho & \text { density } \\ \tau & \text { filling ratio } \\ \varphi & \text { heat flux }\end{array}$

recovery of its operating limit related to the drying of the evaporator. Based on the mechanisms of heat transfer with liquid-vapor phase change, two-phase thermosyphon loops can be used in various applications such in electronic power equipment (Chehade et al., 2015; Khodabandeh, 2005; Khodabandeh, 2004; Khodabandeh and Palm, 2002), the heart of nuclear reactors (Fu et al., 2015), telecommunication equipment (Samba et al., 2013) and also for cooling data center (Tong et al., 2015) or other applications for which the heat fluxes to dissipate are high.

Studies on two-phase thermosyphon loops are relatively recent compared to the conventional twophase thermosyphon. Here we present some research works that have focused on the influence of the nature of the fluid and its load on the thermosyphon 
loop efficiency. Kang et al. (2010) experimentally studied the performance of a compact thermosyphon loop, with a heat transfer length of $106 \mathrm{~mm}$, according to the effect of three parameters: the filling ratio $(5 \%<\tau<50 \%)$, the working fluid (water and methanol), and with or without the deposition of a layer of sintered porous material on the surface of the evaporator. For the maximum heat flux density (equal to $30 \mathrm{~W} / \mathrm{cm}^{2}$ ), the minimum thermal resistance of $0.3{ }^{\circ} \mathrm{C} / \mathrm{W}$ is obtained with the filling ratio of $10 \%$ with methanol, and $30 \%$ with water. Franco and Filippeschi (2013) developed an experimental loop with a measurement of the flow rate by accumulation of a volume of liquid in a reservoir over a given time, called the indirect method. The results indicate a significant increase in circulating flow with fluid load and working pressure, when ethanol is used as a working fluid. This effect is less significant with water. Otherwise, instabilities due to the operating mode are observed. However, the indirect method of flow rate measurement is an intrusive method that decouples the thermo-hydraulic interaction between components during the measurement. Chehade et al. (2014) have developed a thermosyphon loop largely instrumented with pressure and temperature sensors. Water is used as a working fluid and the maximum heat flux density is $14 \mathrm{~W} / \mathrm{cm}^{2}$. Based on this instrumentation, the authors propose an analysis of the mechanisms of liquid-vapor phase change to justify the influence of filling ratio, between 4 and $12 \%$, on the performance of the loop. However, additional information on the phase distribution is needed to confirm their analysis of the loop behavior.

The results of the literature do not allow any further development in the analysis of the thermo-hydraulic couplings sensitive to the filling ratio of two-phase loops. In our study, we have developed a transparent two-phase thermosyphon loop to follow the evolution of the two-phase flows. Ethanol is used as a working fluid and the range of variation of the filling ratio is between 40 and $62 \%$ of the total volume of the loop. The experimental study is conducted for large heat fluxes supplied to the evaporator, ranging from 10 to $60 \mathrm{~W} / \mathrm{cm}^{2}$. The first observations highlight new behaviors such the increase of the drying limit of the evaporator.

\section{EXPERIMENTAL SETUP AND INSTRUMENTATION}

\subsection{Characteristics of the Thermosyphon Loop}

The experimental campaign was conducted on thermosyphon shaped as a loop with a total length of $2.1 \mathrm{~m}$. Figure 1 shows a scheme of this two-phase loop, with the evaporator (1), the condenser (3), the vapor line (2) and the liquid line (4). The main characteristics of these components are summarized in Table 1. Most elements of the loop are transparent allowing the visualization of liquid-vapor flows and the monitoring of the distribution of the fluid load during operating. The evaporator is a copper block in contact with the working fluid on a plain surface with a heating area of $3 \mathrm{~cm}^{2}$ (Fig. 2). The condenser is characterized by a concentric tube exchanger made of transparent glass. The liquid and vapor lines have internal diameters of 3.2 and $9.2 \mathrm{~mm}$ respectively. When a heat flux is supplied to the evaporator, the liquid boils and the produced steam rises through the vapor line and then moves to the condenser. In contact with the walls of the condenser which are cooled by a secondary fluid, the vapor condenses, thus restoring heat to the secondary fluid. Then, the condensate feeds again the evaporator through the adiabatic liquid line.

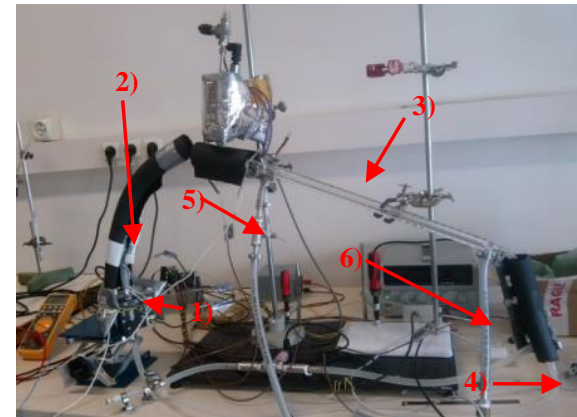

Fig. 1. Experimental setup: 1) Evaporator zone; 2) Vapor line; 3 ) Condenser zone; 4) Liquid line; 5) Inlet of the secondary fluid; 6) outlet of the secondary fluid.

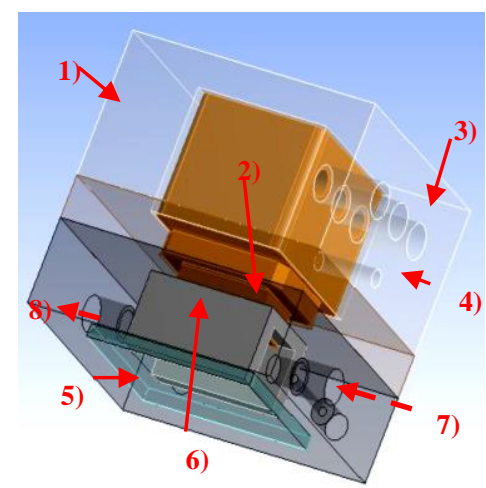

Fig. 2. Design of the evaporator: 1) Teflon blanket; 2) Copper plate; 3) Three compartments; 4) Thermocouple hall; 5) Glass window; 6) Flow chamber; 7) Evaporator inlet; 8) Evaporator outlet.

Table 1 Characteristics of the thermosyphon loop components

\begin{tabular}{|c|c|c|}
\hline Components & Dimensions $[\mathrm{mm}]$ & Material \\
\hline Evaporator & $\begin{array}{c}25 \times 12 \times 14 ; \\
S_{\text {heated }}=300 \mathrm{~mm}^{2}\end{array}$ & $\begin{array}{c}\text { Copper }- \text { Teflon } \\
\text { - Glass }\end{array}$ \\
\hline Vapor line & $\begin{array}{c}\mathrm{L}=579 ; \mathrm{D}_{\mathrm{ex}}=15.4 ; \\
\mathrm{D}_{\text {in }}=9.2\end{array}$ & Silicone tube \\
\hline Condenser & $\begin{array}{c}\mathrm{L}=508 ; \mathrm{D}_{\mathrm{ex}}=14 ; \\
\mathrm{D}_{\mathrm{in}}=10\end{array}$ & Glass \\
\hline Liquid line & $\begin{array}{c}\mathrm{L}=1034 ; \mathrm{D}_{\mathrm{ex}}=6 ; \\
\mathrm{D}_{\text {in }}=3.2\end{array}$ & Silicone tube \\
\hline
\end{tabular}

\subsection{Instrumentation}

In order to collect various information on the 
Table 2 Characteristics and references of the measuring sensors used in the experimental setup

\begin{tabular}{|c|c|c|c|}
\hline Sensor & Type & Quantity & Measuring range \\
\hline Thermocouple & T & 7 & -200 à $350{ }^{\circ} \mathrm{C}$ \\
\hline Manometer & CTE 9003AY4 & 1 & 0 à 3 bar \\
\hline $\begin{array}{c}\text { Differential } \\
\text { manometer }\end{array}$ & PX419-10WDWU5V & 1 & $\begin{array}{c}0 \text { à } 10 \\
\text { in } \mathrm{H}_{2} \mathrm{O}\end{array}$ \\
\hline Flow meter & FT-110 & 1 & 1 à $15 \mathrm{l} / \mathrm{min}$ \\
\hline
\end{tabular}

thermosyphon loop behavior, various measurement sensors were positioned on the loop:

- 4 type-T thermocouples placed, in the fluid, at the inlet and outlet of the various components of the loop;

- 1 sensor for the absolute pressure to measure the vapor pressure at the condenser inlet: this allows to identify the saturation conditions or the presence of incondensable gas;

- 1 sensor for differential pressure with measurement sockets located between the condenser outlet and the evaporator inlet: this measurement, based on a linear pressure drop model, allows determining the liquid flow rate circulating in the loop;

- 1 flow meter turbine and $2 \mathrm{~T}$ type thermocouples placed at the inlet and outlet of the secondary fluid: to determine the heat flux exchanged at the condenser;

- 1 thermocouple positioned inside the heating block.

It is important to note that the selection and positioning of these various sensors have been optimized in order to minimize the interaction of these sensors on the thermo-hydraulic mechanisms of the loop when operating. The characteristics and references of the various measurement sensors are presented in Table 2. These sensors are connected to a NATIONAL INSTRUMENTS NI cDAQ-9174 acquisition unit.

\subsection{Experimental Protocol and Test Conditions}

At first, the two-phase loop is connected to the vacuum pump in its upper part. When the void is achieved in the closed loop, the desired amount of working fluid is injected within the loop thanks to a syringe through a valve, situated in a liquid line, for filling operation. After a first phase of operating of the loop and a return to the rest conditions, a new brief procedure for connecting to the vacuum is performed to remove non-condensable gas residues that could be dissolved in the liquid prior to the filling stage.

Temperatures and pressures at different measurement locations in the loop are recorded at a measurement frequency of $1.95 \mathrm{~Hz}$ using a LabVIEW Signal Express acquisition system managed by a computer. The tests are carried out for different heat fluxes, provided by the Joule effect imposed on heating cartridges inserted in the evaporator block.
Ethanol is used as a working fluid with filling ratios of 40 and $62 \%$ of the total volume of the loop. The heat flux to the evaporator is ranging from 10 to 60 $\mathrm{W} / \mathrm{cm}^{2}$. The flow rate and temperature imposed for the secondary fluid (water) at the inlet of the condenser are $0.003 \mathrm{~kg} / \mathrm{s}$ and $30^{\circ} \mathrm{C}$, respectively.

\subsection{Presentation of the Observables}

Determination of the thermal resistance for each zone:

- The global thermal resistance $\mathrm{R}_{\mathrm{g}}$ of the system is:

$R_{g}=\frac{T_{b}-T_{m}}{Q}$

where

$\mathrm{T}_{\mathrm{m}}=\frac{\mathrm{T}_{\text {in }}+\mathrm{T}_{\text {out }}}{2}$

$\mathrm{Q}=\mathrm{Q}_{\mathrm{in}}=\frac{\mathrm{V}^{2}}{\mathrm{r}}$

- The thermal resistance of the evaporator is:

$\mathrm{R}_{\text {evap }}=\frac{\mathrm{T}_{\mathrm{r}}-\mathrm{T}_{\text {oute }}}{\mathrm{Q}}$

- The thermal resistance of the condenser is:

$\mathrm{R}_{\text {cond }}=\frac{\mathrm{T}_{\mathrm{in}_{\mathrm{c}}-\mathrm{T}_{\mathrm{m}}}}{\mathrm{Q}}$

- The heat exchanged between the cooling fluid (water) and the condenser:

$\mathrm{Q}_{\text {out }}=\dot{\mathrm{m}} \cdot \mathrm{Cp} \cdot\left(\mathrm{T}_{\text {out }}-\mathrm{T}_{\text {in }}\right)$

- The liquid flow rate through the liquid line is:

$\dot{\mathrm{m}}_{\mathrm{liq}}=\frac{2 \cdot \Delta \mathrm{P} \cdot \pi \cdot \mathrm{D}^{4} \rho_{\mathrm{liq}}}{\mu_{\mathrm{liq}} \cdot \mathrm{L}}$

\section{RESULTS AND ANALYSIS}

\subsection{Operating of the Thermosyphon Loop}

Figure 3 shows the temporal evolution of temperatures along the thermosyphon loop for the condition of a heat flux of $100 \mathrm{~W}\left(33.3 \mathrm{~W} / \mathrm{cm}^{2}\right)$ from point $1(t=45 \mathrm{~s})$. For these results, the ethanol filling ratio is equal to $62 \%$ of the total volume of the loop. For this filling ratio, the liquid level in the vapor line is $20 \mathrm{~mm}$ above the evaporator, and completely fills the liquid line (liquid meniscus at the junction between the condenser and the liquid line). In phase 2 of the evolution of the temperatures, the heat flux accumulates in the copper cylinder head of the evaporator, then progressively heats the liquid contained in the evaporator by natural convection 


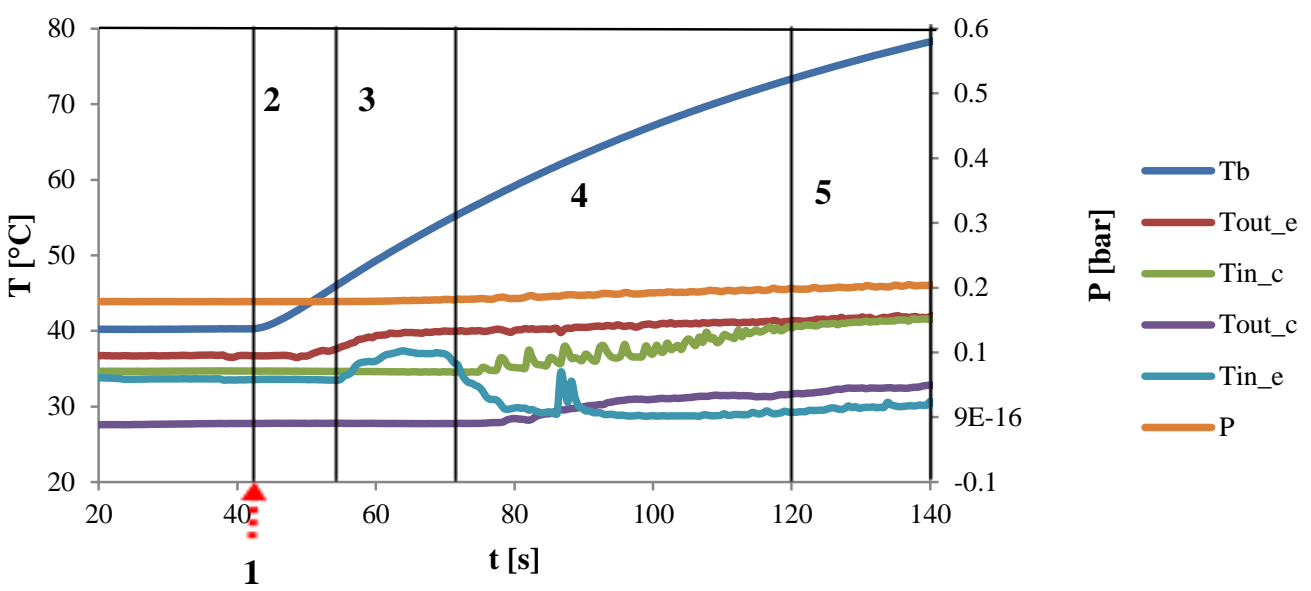

Fig. 3. Time variation of temperature and pressure for Ethanol at: $\tau=62 \%$ and $Q=100 \mathrm{~W}$.

induced by the difference of temperature between the wall and the liquid. This mechanism is highlighted by the progressive rise in temperature at the evaporator outlet. From phase 3, due to the high imposed heat flux, the boiling mechanism occurs at the heated wall of the evaporator. First, vapor bubbles, formed in the evaporator, condense in the sub-cooled liquid present in the region of the evaporator. Due to the evaporator confinement, the boiling phenomenon generates a large stirring of the liquid, thereby contributing to an increase in the temperature of the fluid at the evaporator.

For times between $\mathrm{t}=70 \mathrm{~s}$ and $120 \mathrm{~s}$ (phase 4), as the liquid "present in the vapor line" heats up, the vapor bubbles tend to accentuate the amplitude of liquid movements in the vapor line up to drag the liquid until the condenser. It is this phenomenon which explains, in a first step, the increase of temperature at the inlet of the condenser. For $t>$ $120 \mathrm{~s}$ (phase 5), the liquid reached the equilibrium temperature corresponding to the saturation temperature $\left(T_{\text {liq }}=T_{\text {vap }}\right)$. The entrainment of liquid until the condenser depends upon the initial fluid load and the relative position of the condenser towards the evaporator. The decrease of the temperature of the fluid at the inlet of the evaporator is due to the circulation of the liquid in the liquid line from the condenser to the evaporator. Indeed, the condensing vapor and the amount of liquid entrained by the steam from the evaporator into the condenser induce a hydrostatic pressure effect at the condenser outlet which tends to push the liquid towards the evaporator where the pressure is lower. It can be noted that the liquid exits from the condenser in a sub-cooled state and continues to sub-cool along the liquid line by exchanging with the ambient air. The steady state is obtained after 15 minutes of operating of the thermosyphon loop.

After reaching the steady state, Fig. 4 shows the time evolution of various parameters, namely the inlet and outlet temperatures of the evaporator, the inlet and outlet temperatures of the condenser, the difference of temperatures of the cooling water and the differential pressure. The presence of peaks in the signals is explained by the entrainment of the liquid towards the condenser.

\subsection{Influence of the Filling Ratio}

We found a significant influence of the fluid load on the dynamic behavior of the thermosyphon loop. In the previous section, we discussed the interaction between the vapor steam produced in the evaporator and subjected to an upward movement, with the liquid phase contained in a part of the vapor line and subjected to gravity. The extension of this interaction zone in the vapor line is particularly sensitive to the liquid load. From certain fluid loads and heat fluxes, the extension of this interaction zone (two-phase flow zone) tends to extend over the entire vapor line. Liquid can then be dragged into the condenser. This liquid entrainment induces an increase in the flow circulating along the thermosyphon and provokes an additional heat transfer. In fact, the heat flux collected by the secondary fluid is due on the one hand from the latent heat of the condensing vapor phase and on the other hand from the sensible heat of the saturated liquid entrained and then sub-cooled. To identify the importance of the entrainment phenomenon of the liquid phase to the condenser, we perform a measurement of the differential pressure at the liquid line. The differential pressure signal shows significant fluctuations of the order of $50 \mathrm{~Pa}$ around a mean value. These pressure fluctuations result from the intensity of the boiling mechanism in a confined environment and at high heat fluxes. Figure 5 displays the averaged differential pressure versus the supplied heat flux for two ethanol filling ratios, 40 and $62 \%$. When $Q=90 \mathrm{~W}$, the pressure difference measured on the liquid line is 6 times larger for the highest filling ratio. On Fig. 6 are presented the flow rates calculated for the two filling ratios, assuming that the pressure difference is related to a linear pressure drop along the liquid line. There is a factor of the order of 10 between the calculated flow rates. It should be noted that the calculated flow rates are for the moment more qualitative than quantitative because of the dynamic regime of the flow in the liquid line due to the hydrodynamic interactions with the boiling 
mechanism at the evaporator. For the case of $40 \%$ of the filling ratio, the visualizations confirm that no liquid is trained to the condenser from the vapor line regardless of the imposed heat flux.
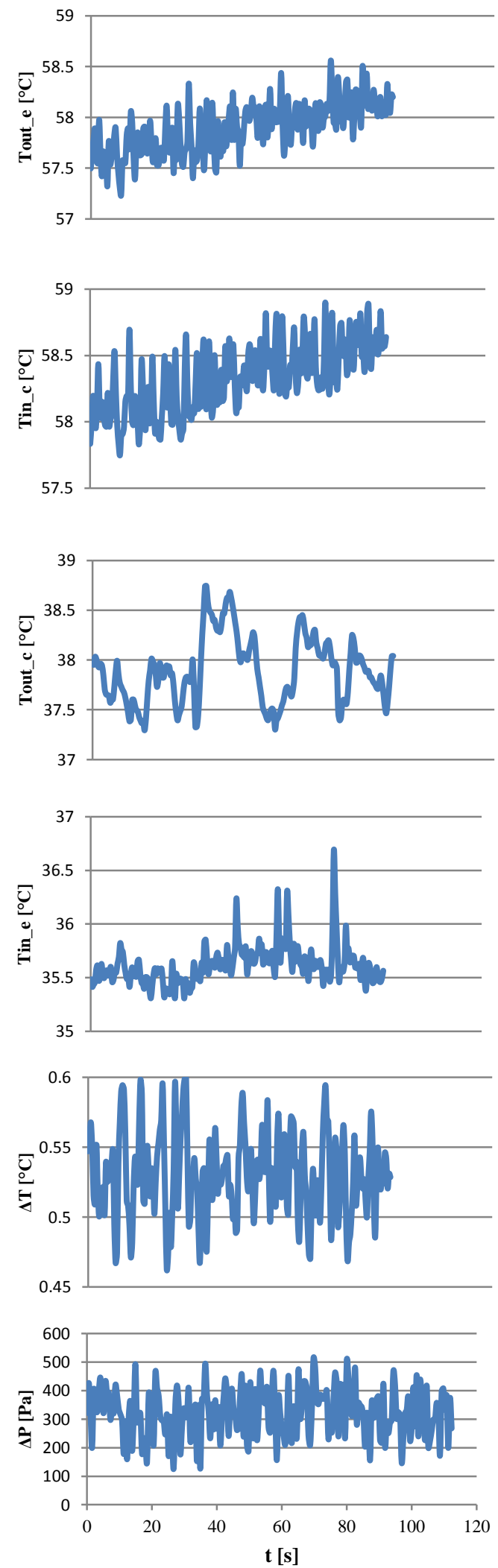

Fig. 4. Temporal signals of various parameters for Ethanol at: $\tau=62 \%$ and $Q=90 \mathrm{~W}$.

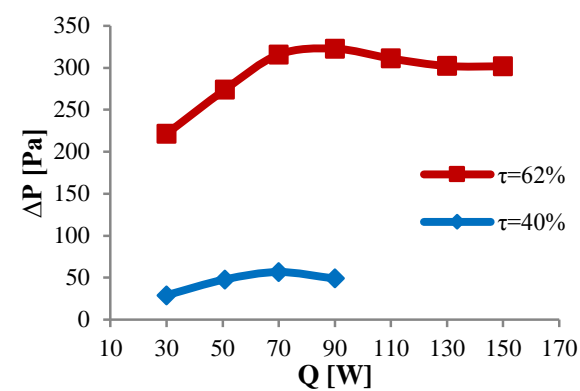

Fig. 5. Variation of the differential pressure vs. heat flux for two ethanol filling ratios.

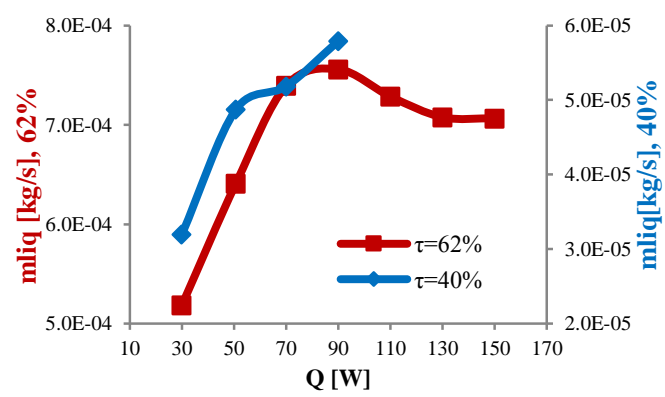

Fig. 6. Evolution of the liquid flow rate in the liquid line vs. heat flux for two ethanol filling ratios.

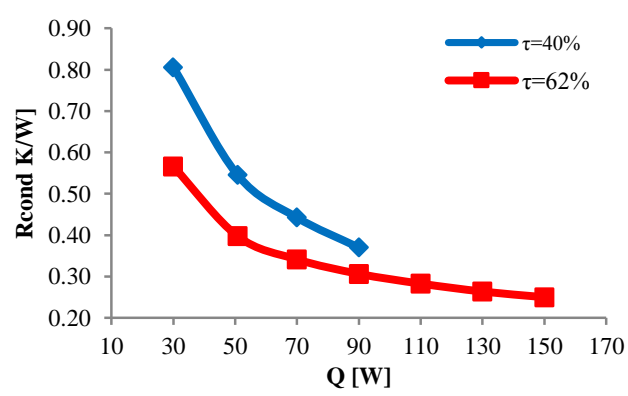

Fig. 7. Variation of the thermal resistance at the condenser vs. heat flux for two ethanol filling ratios.

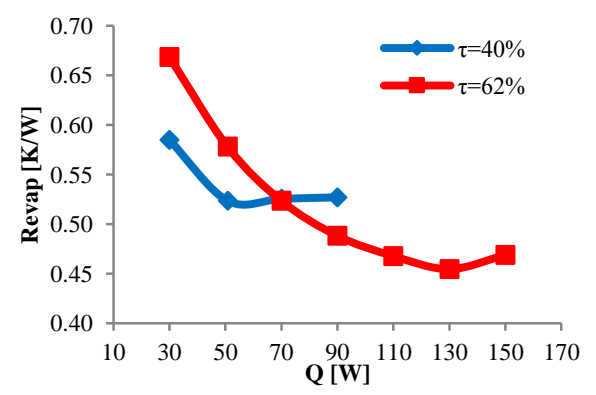

Fig. 8. Variation of the thermal resistance at the evaporator vs. heat flux for two ethanol filling ratios.

The change of mechanism for the two filling ratios also contributes to a modification of the heat transfer. Figures 7,8 and 9 respectively show the thermal resistances at the condenser, the evaporator, and overall for the thermosyphon loop. At lower heat fluxes, heat transfer at the evaporator is more favorable for the low filling rate. The steam produced 
encounters less resistance to its evacuation, thus improving heat exchange. At the condenser, heat transfer is improved for large loads where liquid is trained with the steam, whatever the heat flux. In the inclined condenser, the condensation regime is of stratified type. The consequence of these mechanisms results in an overall enhancement of the heat transfer for the large loads.

Among the results obtained, the most striking effect concerns the increase of the operating limit of the thermosyphon loop for the high filling ratio. The operating limit of the two-phase loop corresponds to the appearance of the boiling crisis on the surface of the evaporator. This effect results from the increase in the amount of sub-cooled liquid at the inlet of the evaporator for the high filling ratio. The fraction of vapor in the evaporator is then decreased by the interaction of the vapor and the sub-cooled liquid, thus facilitating the rewetting of the wall of the evaporator.

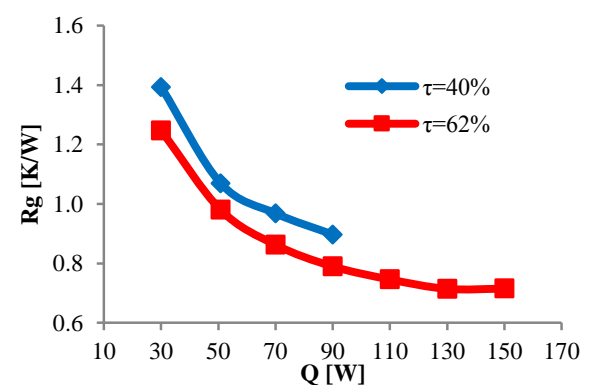

Fig. 9. Variation of the global thermal resistance vs. heat flux for two ethanol filling ratios.

\subsection{Influence of the Hydraulic Singularity}

In the previous results, we have shown the importance of thermo-hydraulic couplings within the thermosyphon loop on its performance. A singularity has been placed at the level of the liquid line, the idea of adding this hydraulic singularity along the liquid line aims to modify this hydrodynamic coupling. The singularity generates a resistance to the flow of the liquid which induces the accumulation of liquid in the condenser and consequently leads to an increase in pressure compared with the case without singularity (Fig. 10). We can see in this case and according to the values of the thermal resistances, the singularity has improved the mass transfer at the evaporator, but this singularity has decreased the total efficiency of the loop. So if the overall thermal resistance of the loop is degraded by the addition of this singularity, the relative weights of the different thermal resistances between the evaporator and the condenser have been modified. Thus, the thermal resistance at the evaporator is improved while that at the condenser is degraded. The transfer of the fluidic load can explain this modification of the thermal resistances from the vapor line to the condenser. For a given heat flux and therefore a given circulating liquid flow, the pressure losses along the liquid line by the addition of the singularity increase. In order to supply the evaporator with liquid, it is therefore necessary to compensate this increase in pressure. This new hydraulic resistance will first induce an accumulation of liquid at the outlet of the condenser. Increasing the liquid level in the condenser will cause additional hydrostatic pressure and thus compensates the addition of hydraulic resistance. Simultaneously, this addition of load at the condenser outlet induces a reduction of the liquid load in the so-called vapor line. This mass transfer from the so-called vapor line to the outlet of the condenser tends to enhance the heat transfer at the evaporator: less liquid in the so-called vapor line implies less hydraulic resistance for the evacuation of the steam produced at the evaporator. However, an increase in the liquid level at the outlet of the condenser tends to reduce the efficient surface of heat exchange, and therefore to degrade the thermal resistance at the condenser.

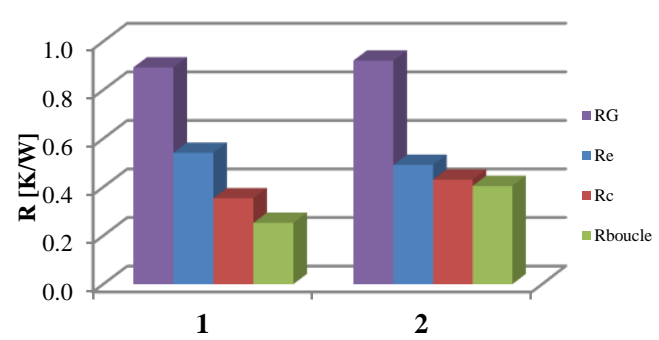

Fig. 10. Variation of the thermal resistance with (1) and without (2) the singularity.

\section{CONCLUSION}

In this work, the experimental observations reveal new thermo-hydraulic behaviors of two-phase thermosyphon loops for high filling ratios and high heat fluxes. Liquid is trained to the condenser by the steam produced in the evaporator under the effect of the confinement of the phases. This mechanism induces a significant increase in the flow rate flowing along the loop which has the effect of refilling the evaporator with a larger amount of sub-cooled liquid. The most noticeable effect, at the global scale of the loop, is an increase in the evaporator drying limit, from $30 \mathrm{~W} / \mathrm{cm}^{2}$ with a filling ratio of $40 \%$, to 50 $\mathrm{W} / \mathrm{cm}^{2}$ for a filling ratio of $62 \%$. The experimental campaign will be continued to better quantify the role of the various parameters of the loop favorable to these effects of entrainment of the liquid phase until the condenser.

\section{REFERENCES}

Chehade, A. A., H. Louahlia-Gualous, S. Le Masson, I. Victor and N. Abouzahab-Damaj (2014). Experimental investigation of thermosyphon loop thermal performance. Energy Conversion and Management 84, 671-680.

Chehade, A., H. Louahlia-Gualous, S. Le Masson and E. Lépinasse (2015). Experimental investigations and modeling of a loop thermosyphon for cooling with zero electrical consumption. Applied Thermal Engineering 87, 559-573.

Franco, A. and S. Filippeschi (2013). Experimental 
S. Adjmi et al. /JAFM, Vol. 12, Special Issue, pp. 71-77, 2019.

analysis of Closed Loop Two Phase Thermosyphon (CLTPT) for energy systems. Experimental Thermal and Fluid Science 51, 302-311.

Fu, W., X. Li, X. Wu and Z. Zhang (2015). Investigation of a long term passive cooling system using two-phase thermosyphon loops for the nuclear reactor spent fuel pool. Annals of Nuclear Energy 85, 346-356.

Kang, S. W., M. C. Tsai, C. S. Hsieh and J. Y. Chen (2010). Thermal Performance of a Loop Thermosyphon. Tamkang Journal of Science and Engineering 13(3), 281-288.

Khodabandeh, R. (2004). Thermal performance of a closed advanced two-phase thermosyphon loop for cooling of radio base stations at different operating conditions. Applied Thermal Engineering 24, 2643-2655.

Khodabandeh, R. (2005). Heat transfer in the evaporator of an advanced two-phase thermosyphon loop. International Journal of Refrigeration 28, 190-202.

Khodabandeh, R. and B. Palm (2002). Influence of system pressure on the boiling heat transfer coefficient in a closed two-phase thermosyphon loop. International Journal Thermal Sciences 41, 619-624.

Samba, A., H. Louahlia-Gualous, S. Le Masson and D. Nörterhäuser (2013). Two-phase thermosyphon loop for cooling outdoor telecommunication equipments. Applied Thermal Engineering 50, 1351-1360.

Tong, Z., T. Ding, Z. Li and X. Liu (2015). An experimental investigation of an R744 twophase thermosyphon loop used to cool a data center. Applied Thermal Engineering 90, 362365 . 